\title{
Building Infrastructure Distributed Database in CV. Cipta Solusi Sejahtera
}

\author{
Benny Wijaya \\ STMIK Atma Luhur \\ J1. Jend. Sudirman, Selindung, Pangkalpinang \\ benny.wijaya1@gmail.com
}

\author{
Boy Valentino \\ STMIK Palcomtech \\ Jl. Basuki Rahmat No. 5 Palembang
}

\begin{abstract}
Abstrak- Sistem basis data terdistribusi merupakan suatu bentuk arsitektur sistem dimana komputer-komputer yang berdiri secara otonom dapat saling berkomunikasi dan berbagi resource tanpa memperdulikan dimana komputer itu berada dan platform yang digunakan. Masalah atau kendala yang dialami karena keterbatasan ruang disk pada komputer client dapat mengakibatkan ketidak efisien-an kinerja karyawan pada perusahaan saat penyimpanan data. Sehingga untuk mengatasinya diperlukan suatu sistem basis data dan suatu modular yang memungkinkan administrator dapat mengatur quota untuk memenuhi kebutuhan ruang disk dalam penyimpanan data. Administrator dapat mengendalikan pemanfaatan ruang disk pada tingkat volume dengan menetapkan batas-batas untuk ruang disk yang dialokasikan pada setiap client.
\end{abstract}

Kata Kunci: sistem basis data terdistribusi, modular, quota, volume

\section{PENDAHULUAN}

Seiring dengan perkembangan ilmu pengetahuan dan teknologi yang semakin canggih dan kemajuan perekonomian yang semakin pesat, tuntutan akan kebutuhan informasi berupa data dalam kehidupan sehari-hari juga semakin meningkat. Oleh sebab itu, tidak heran jika untuk menjalankan suatu perusahaan dibutuhkan teknologi informasi dan komunikasi. Manusia membutuhkan teknologi informasi dan komunikasi untuk dapat saling bertukar informasi.

CV. Cipta Solusi Sejahtera merupakan perusahaan yang bergerak dalam bidang konsultan IT, pada jaringan komputer di CV . Cipta Solusi Sejahtera terdapat beberapa server yang dapat diakses oleh karyawan melalui personal computer, server-server tersebut antara lain web server dan DNS server.

Kapasitas ruang penyimapan yang digunakan pada personal komputer client masih sangat terbatas karena media penyimpanan yang digunakan belum mencukupi untuk menyimpan file-file yang besar (software,video tutorial) sehingga akan menghambat kinerja karyawan pada perusahaan.
Masalah atau kendala yang dialami karena keterbatasan ruang disk pada komputer client dapat mengakibatkan ketidak efisienan kinerja karyawan pada perusahaan saat penyimpanan data, Sehingga untuk mengatasinya diperlukan suatu sistem basis data dan suatu modular yang memungkinkan administrator dapat mengatur quota untuk memenuhi kebutuhan ruang disk dalam penyimpanan data.

Untuk membangun sistem basis data tersebut akan digunakan Glusterfs, GlusterFS adalah clustered file sistem basis data yang bersifat open source yang dapat beroperasi dengan kapasitas petabyte dan menangani ribuan client. GlusterFS menggabungkan disk, memori dan pengolahan basis data dari beberapa modul server dalam sebuah ruang tunggal. GlusterFS didesain untuk memenuhi kebutuhan ruang penyimpanan bagi pengguna serta dapat membackup data jika komputer client mengalami kerusakan, sehingga data yang telah tersimpan pada komputer server akan tetap aman.

\section{A. Jaringan Komputer}

Menurut [1] Jaringan komputer adalah kumpulan dari beberapa komputer, baik jaringn komputer yang bersekala kecil seperti dirumah atau dikantor maupun yang bersekala besar seperti antarkot dan provinsi, atau jaringan komputer yang mendunia (internasional) seperti antar benua atau antardunia, dimana komputer-komputer tersebut saling berhubungn dn terorganisir(berintegrasi).

\section{B. Basis Data Terdistribusi}

Basis data terdistribusi (Database terdistribusi) adalah kumpulan database yang disimpan di banyak komputer pada lokasi yang berbeda-beda dan menampilkan ke user sebagai single database. Dalam sebuah database terdistribusi, database disimpan pada beberapa komputer. Komputerkomputer dalam sebuah sistem terdistribusi berhubungan satu sama lain melalui bermacammacam media komunikasi seperti high-speed buses atau telephone line. 
Sebuah sistem database terdistribusi berisikan sekumpulan site, di mana tiap-tiap site dapat berpartisipasi dalam pengeksekusian transaksitransaksi yang mengakses data pada satu site atau beberapa site. Tiap-tiap site dapat memproses transaksi lokal yaitu sebuah transaksi yang mengakses data pada satu site di mana transaksi telah ditentukan. Sebuah site juga dapat mengambil bagian dalam mengeksekusi transaksi global yaitu transaksi yang mengakses data pada site yang berbeda di mana transaksi telah ditentukan, atau transaksi yang mengakses data pada beberapa site yang berbeda.[2]

\section{GlusterFS}

Menurut [3] GlusterFS adalah clustered file system yang bersifat open source yang dapat beroperasi dengan kapasitas petabyte dan menangani ribuan client. GlusterFS menggabungkan disk, memori dan pengolahan data dari beberapa modul server dalam sebuah ruang tunggal. GlusterFS di desain untuk memenuhi kebutuhan ruang penyimpanan bagi pengguna dan dapat memberikan kinerja yang luar biasa untuk beban kerja yang beragam.

Arsitektur GlusterFS bersifat modular yang memungkinkan administrator menambah atau mengurangi modul server sesuai dengan kebutuhan pengguna. Sebagai contoh, administrator dapat mengkonfigurasi sistem server mandiri dengan cepat menggunakan GlusterFS dan kemudian mengembangkan sistem sebagai kebutuhan tumbuh.

GlusterFS memiliki kemampuan mengatur quota penggunaan ruang disk dengan direktori atau volume. Administrator dapat mengendalikan pemanfaatan ruang disk pada tingkat direktori dan/atau volume dengan menetapkan batas-batas untuk ruang disk dialokasikan di setiap tingkat dalam volume dan hirarki direktori.

GlusterFS dirancang untuk komputasi awan dengan performa tinggi, tidak seperti pusat data tradisional, lingkungan awan membutuhkan multisewa bersama dengan kemampuan untuk tumbuh atau menyusut sumber daya sesuai permintaan.

\section{METODE PENELITIAN}

\section{A. Jenis Penelitian}

Jenis penelitian yang dilakukan oleh penulis adalah Penelitian Terapan. Penelitian terapan adalah penyelidikan yang hati-hati, sistematik dan terus-menerus terhadap suatu masalah dengan tujuan untuk digunakan dengan segera pada keperluan tertentu. Hasil penelitian tidak perlu sebagai suatu penemuan yang baru, tetapi merupakan aplikasi baru dari penelitian yang telah ada [4].

B. Teknik Pengembangan Sistem

Untuk mengerjakan laporan ini penulis menggunakan teknik pengembangan sistem NDLC ( Network DevelopmentLife Cycle ).

Menurut[5], NDLC yaitu suatu pendekatan proses dalam komunikasi data yang menggambarkan siklus yang tiada awal dan akhirnya dalam membangun sebuah jaringan komputer mencakup sejumlah tahapan yaitu analisis, desain, monitoring, simulasi prototype dan implementasi, dimana posisi perusahan dalam siklus tersebut sesuai dengan kondisi jaringan komputer yang dimiliki saat ini yaitu pada tahap analisis menuju ke desain.

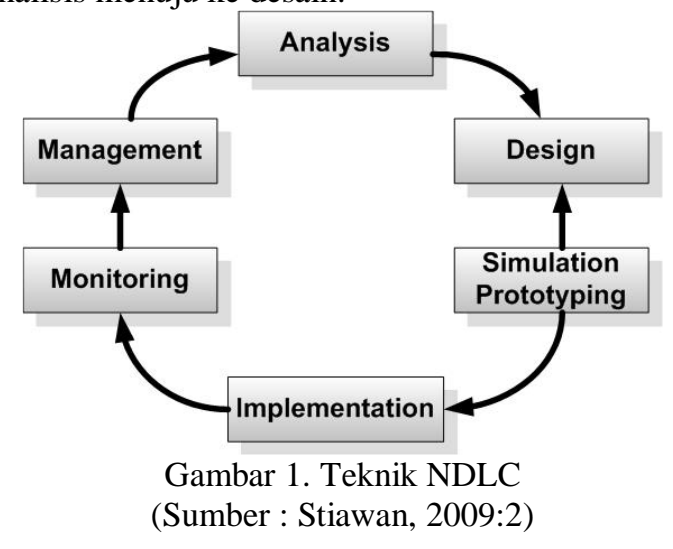

1. Analisis

Pada tahap analisis ini dilakukan studi pendahuluan dengan fokus menganalisa permasalahan yang ada melalui metode observasi dan wawancara. Dari permasalahan kemudian di pilih beberapa alternatif solusi yang bisa diterapkan.

2. Desain

Pada tahap desain dibuatlah infrastuktur topologi jaringan yang berbentuk client-server dan didalam jaringan tersebut ditempatkan sistem basis data terdistribusi.

\section{Simulation Prototype}

Pada tahapan ini akan dibangun server basis data terdistribusi menggunakan Glusterfs

Sistem basis data yang digunakan dapat beroperasi dengan kapasitas yang besar dan menangani ribuan client.

\section{Hasil Analisis Data Penelitian}

Untuk menjamin ketersediaan ruang penyimpanan data pada komputer client bisa dimanfaatkan teknologi glusterfs, yaitu dengan membuat 1 unit server yang berfungsi sebagai 
media untuk mengatur quota penggunaan ruang disk dengan directory atau volume. Untuk itu akan dilakukan perancangan teknologi glusterfs yang diharapkan menjadi suatu solusi pada CV . Cipta Solusi Sejahtera.

\section{Analisis Permasalahan}

Keterbatasan kapasitas harddisk menjadi hal utama yang dikedepankan karena tidak mencukupi untuk menyimpan file-file serta backup data pada komputer client yang besar (software, video tutorial) mengakibatkan proses penyimpanan data menjadi tidak efesien dan akan menghambat kerja karyawan pada perusahaan.

\section{E. Desain struktur Topologi yang diusulkan}

Menggambarkan semua komponen dalam sistem yang saling terhubung melalui jaringan, dimana satu buah server yang menyediakan service untuk client. Client adalah komputer yang melakukan permintaan service yang disediakan oleh server, untuk membuat volume terdistribusi merupakan gabungan media penyimpanan menjadi sebuah media penyimpanan tunggal dengan kapasitas besar beserta backup data yang nantinya diakses oleh pengguna pada sisi client.

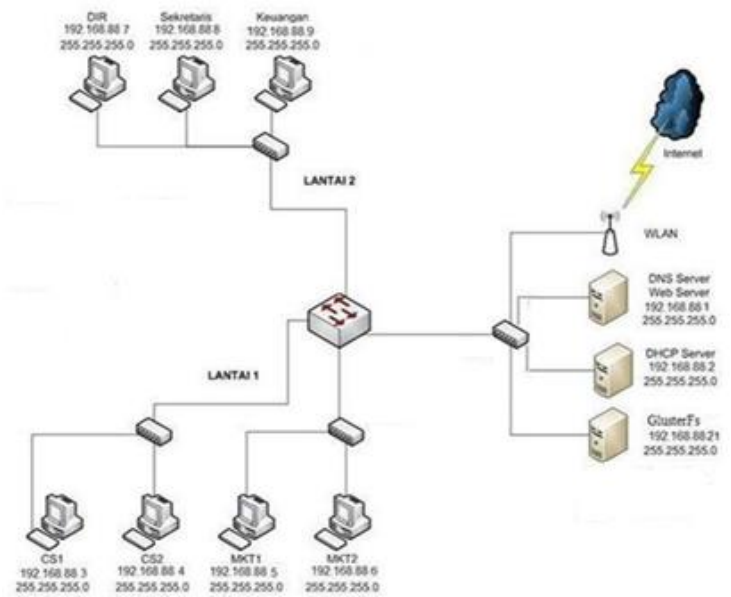

Gambar 2. Topologi yang diusulkan

\section{F. Installasi GlusterFs}

Untuk Instalasi glusterfs dilakukan pada server, setelah instalasi Debian server selesai dengan tools apt-get. Terlebih dahulu login sebagai root sebelum melakukan instalasi dengan perintah \#su, Sebelum instalasi, lakukan update repository server Debian \#apt-get update.

\section{G. Instalasi paket GlusterFs server}

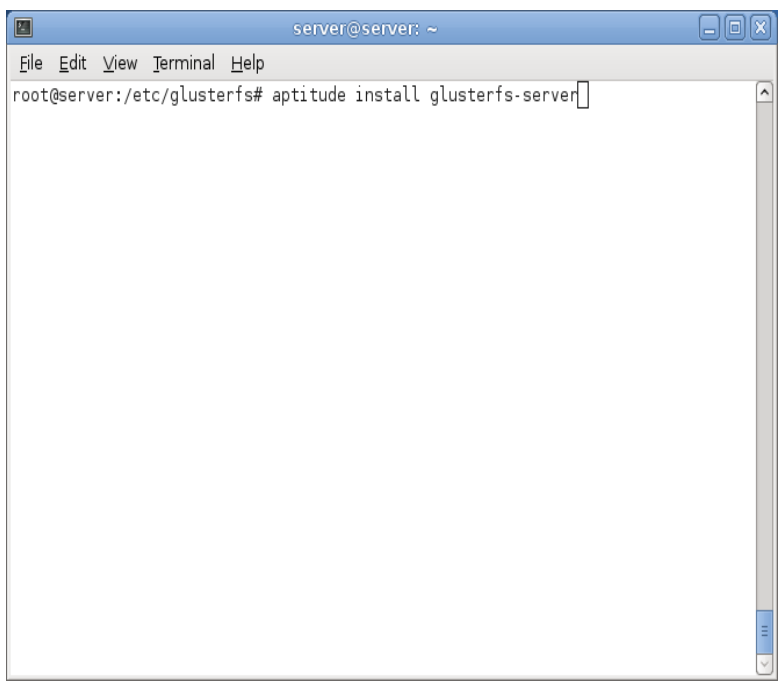

Gambar 3. Instalasi paket GlusterFs server

- Untuk menginstalasi paket glusterfs server menggunakan perintah :

\section{\#aptitude install glusterfs-server}

H. Edit file: /etc/hosts di Pc server dan client glusterfs

- Agar server dapat terhubung pada client maka dilakukan proses resolve server-client, edit file: /etc/hosts pada server tersebut hingga seperti berikut:

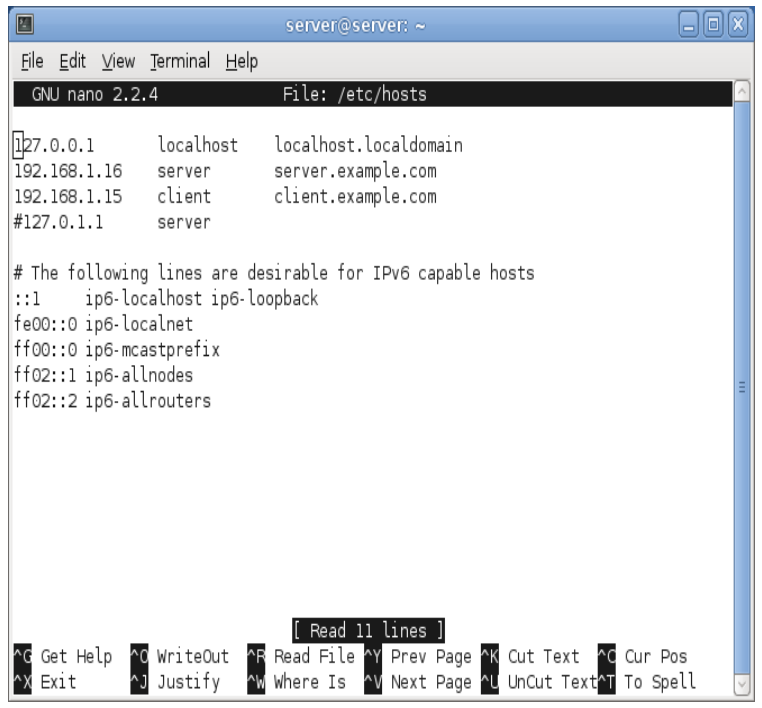

Gambar 4. Edit file: /etc/hosts di Pc server dan client glusterfs 
- Lanjutkan dengan membuat beberapa direktori pada server glusterfs.

\#mkdir - p /data/export

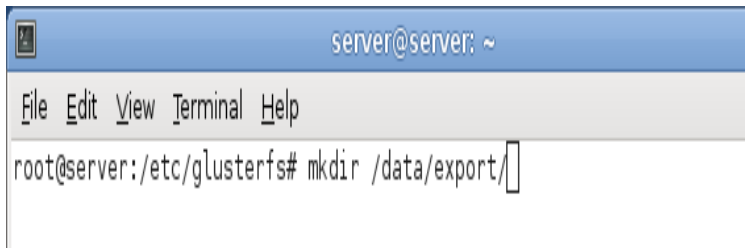

Gambar 5. Membuat direktori pada server glusterfs

- Edit file konfigurasi glusterfs di server glusterfs. Backup file configurasi asli letc/glusterfs/glusterfsd.vol menjadi letc/glusterfs/glusterfsd.vol_orig terdahulu kemudian lakukan proses edit file letc/glusterfs/glusterfsd.vol agar dapat mendefinisikan direktori yang akan diexport(/data/export), dan client mana yang akan di izinkan untuk melakukan koneksi 192.168.1.15 Cilent.

\#cp/etc/glusterfs/glusterfsd.vol /etc/glusterfs/glusterfsd.vol orig \#nano /etc/glusterfs/glusterfsd.vol

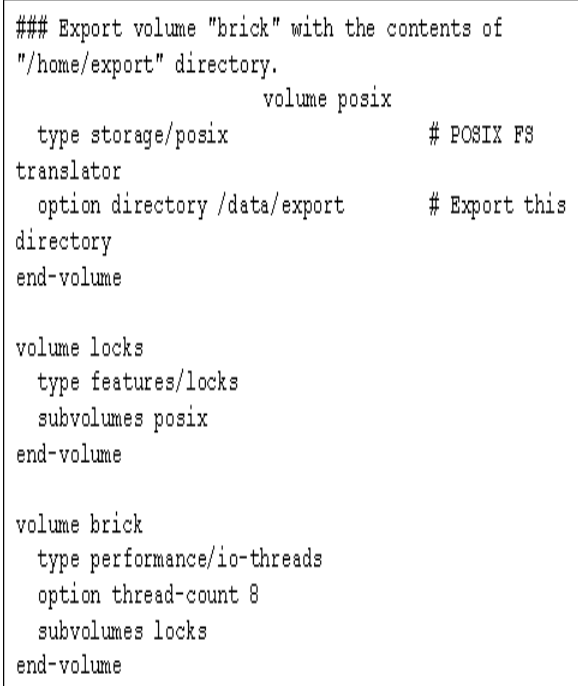

Gambar 6. konfigurasi glustrfsd

- Restart service glusterfs server

\#/etc/init.d/glusterfs-server restart

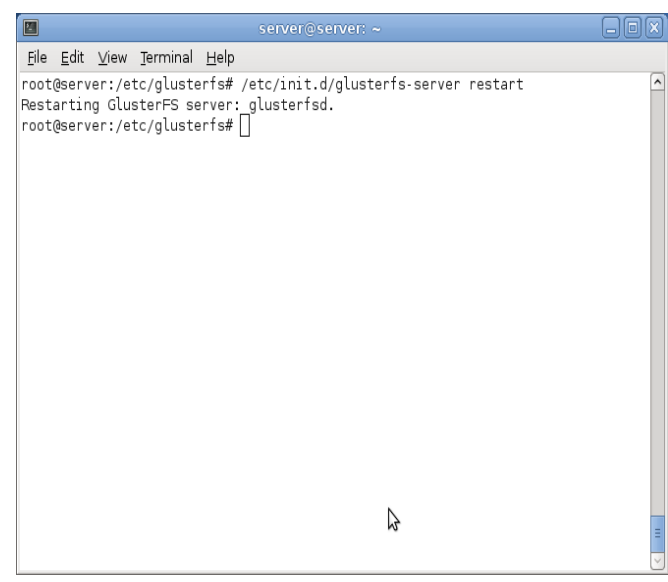

Gambar 7. restart service glusterfs server

- Setelah melakukan konfigurasi dari sisi server, selanjutnya menkonfigurasi client glusterfs pada gambar berikut :

\#aptitude install glusterfs-client glusterfsserver

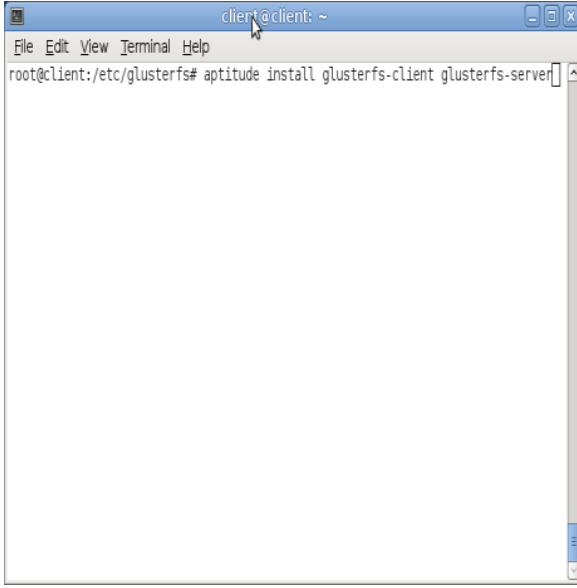

Gambar 8. instalasi paket glusterfs pada client

- Membuat direktori /mnt/glusterfs yang nantinya akan digunakan untuk menaruh hasil mount direktori share glusterfs

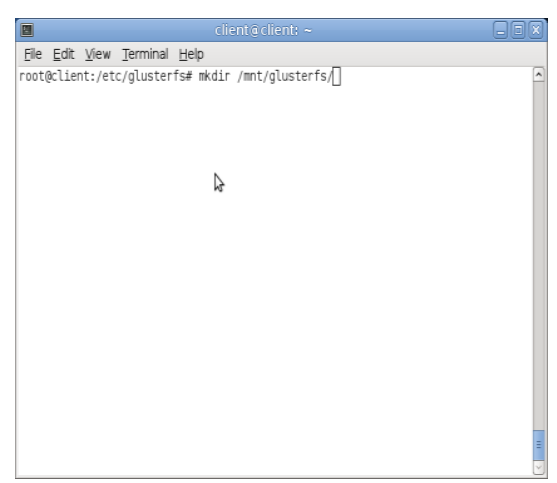

Gambar 9. Membuat direktori /mnt/glusterfs 
- Setelah membuat direktori, selanjutnya melakukan proses mount filesystem glusterfs dengan menggunakan perintah

\section{\#mount}

Seperti terlihat pada gambar 10 .

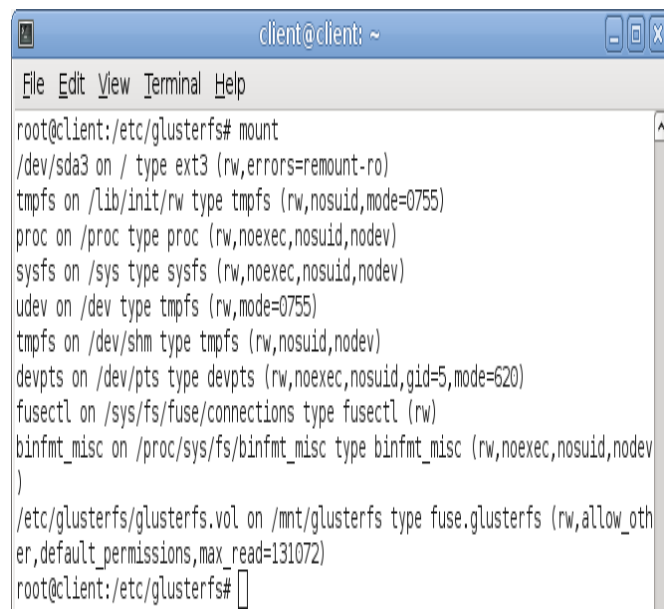

Gambar 10. Proses Mount glusterfs

- Mengkonfigurasi remote host glusterfs agar komputer server-client dapat saling terkoneksi

\section{\#gedit /etc/glusterfs/glusterfsd.vol}

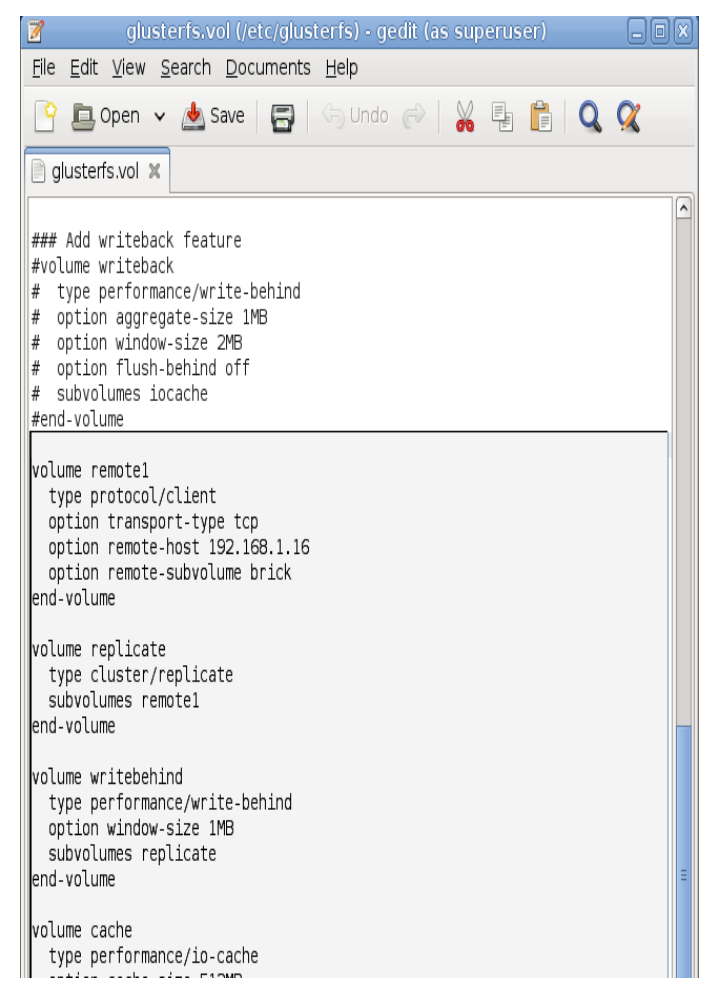

Gambar 11. remote host
- Untuk memastikan kalau perubahan file /etc/fstab ini sudah dapat berjalan dengan baik pada client glusterfs, lakukan proses reboot.

\section{\#sudo reboot}

Gambar 12. proses reboot

- Berikutnya, lakukan serangkaian tahap uji coba caranya, pindah ke pc client, lalu buat beberapa file test sebagai berikut :

\#touch

$/$ mit/glusterfs/testl

Gambar 13. membuat beberapa file test pada pc client glusterfs

- Cek direktori /data/export di server, maka akan terlihat bagian dari file/direktori yang membentuk bagian dari file/direktori yang menjadi glusterfs share client

$\# / s-l /$ datalexport

Gambar 14. melihat isi direktori

- Pengujian pada pc client melalui consol menggunakan perintah $d f-h$

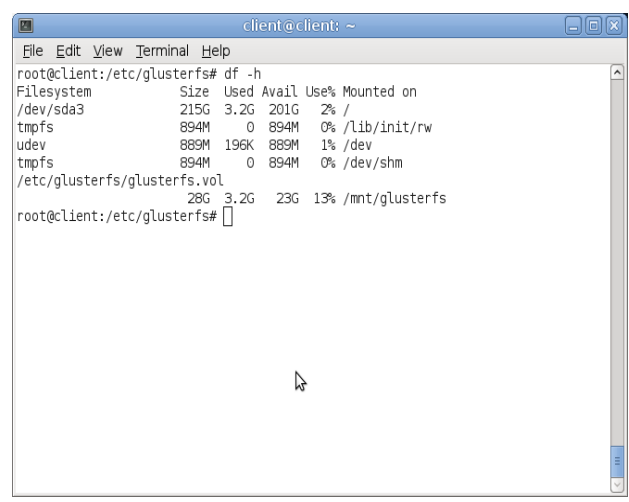

Gambar 15. Uji coba pada PC Client menggunakan consol yang telah berhasil

\section{HASIL IMPLEMENTASI DAN PENGUJIAN}

Pada komputer client dilakuan percobaan tes ping dari komputer client ke komputer server untuk memastikan pada masing - masing komputer sudah terkoneksi dengan baik pada gambar 15 terlihat sudah terkoneksinya antar client. 


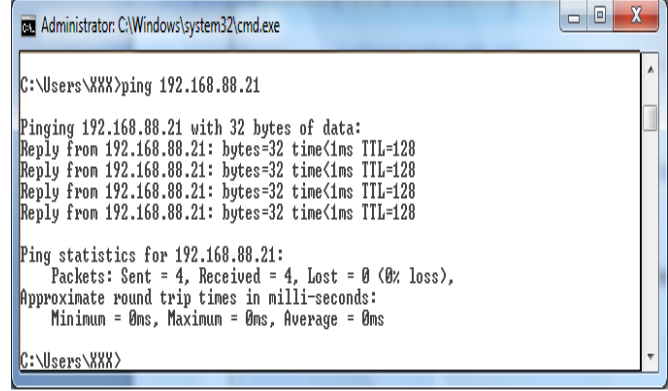

Gambar 16. Tes ping

Pada gambar 17 dilakukan percobaan sharing file dari client 1 ke client lain untuk memastikan file dapat terdistribusi antar client.

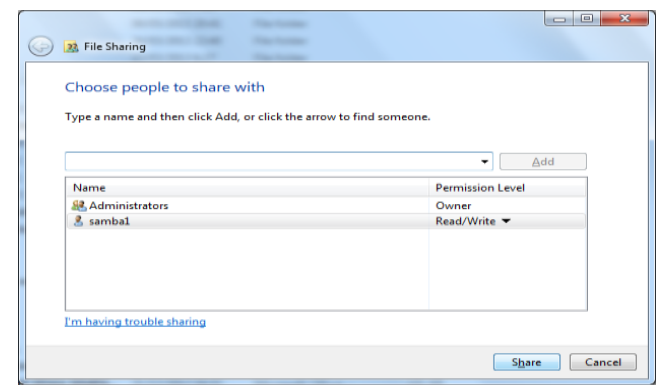

Gambar 17. Sharing file

Hasil percobaan akhir yang telah dilakukan dapat dibuktikan dengan file yang tampil ketika client 1 mengirimkan data yang ingin di distribusikan ke client lain yang tampil pada network.

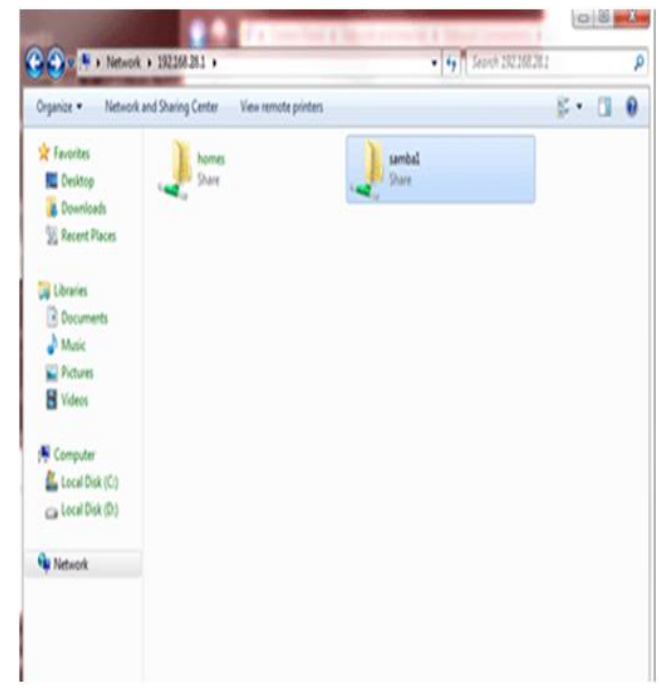

Gambar 18. Direktori yang berhasil di-sharing

\section{KESIMPULAN}

Dengan penggunaan glusterfs, investasi terhadap penggunaan hardware dapat ditekan lebih rendah karena tidak perlu ada penambahan perangkat komputer client dan perangkat tambahan secara fisik tetapi hanya mendayagunakan kapasitas media penyimpanan yang sudah ada.

\section{DAFTAR PUSTAKA}

[1] Suarna, Nana. 2007. Petunjuk Teoritis Pengantar Lan. PT. YRAMA WIDYA: Bandung.

[2] Sumarsono. 2010. Sistem Basis Data Terdistribusi Client-Server 3-Tier Berbasis Komponen. [online]. Tersedia : http://www.digilib.uinsuka.ac.id/7899/1/sumarsono $\% 20$ sistem $\% 20$ b asis $\% 20$ data $\% 20$ terdistribusi\% 20clientserver $\% 203$ tier\%20berbasis\%20komponen [Akses :21 juni 2013].

[3] Suryadi. 2012. Membuat Media Penyimpanan Terdistribusi Menggunakan Glusterfs pada Debian Squeeze. [online]. Tersedia:

http://www.slideshare.net/abufarros1/mediape nyimpananterdistribusideganglusterfspadadeb iansqueeze [Akses : 21 juni 2013].

[4] Andi. 2011. Basis Data. Wahana Komputer: Semarang.

[5] Saebani, Beni Ahmad. 2008. Metode Penelitian. CV Pustaka Setia: UIN Sunan Gunung Djati Bandung.

[6] Listanto, Virgiawan. 2011. Teknik Jaringan Komputer. Prestasi Pustaka Publisher : Jakarta. Raharjo, Budi. Belajar Otodidak membuat Database menggunakan MySql. Informatika Bandung. 2011.

[7] Muhamad, Dedi, Pebri, Dian. 2012. Teknik Komputer Jaringan. Inti Prima Promosindo:Jakarta.

[8] Sidiq, Zen, Wina, Onno. 2002. Samba, Jembatan Windows dan Linux. PT. Elex Media Komputindo: Jakarta. 